\title{
Dificultades en el registro y transmisión de un arte fugaz.
}


DIFFICULTIES IN THE RECORD AND TRANSMISSION OF A

FUGAZ ART.

\section{ABSTRACT}

Since the second half of 20th century, artistic interventions have become independent of the jaded and constant aesthetic, mimetic and mathematical components. The impossibility of guarding the work as an object demands new mechanisms that register an art as changing as it is capricious. With the advances in technology, digital photography and innovations in the field of art, artists will begin to record their interventions, using cameras and small recordings to immortalize their works. We dedicate this research to work through a representation of emerging authors, difficulties in the registration of artistic works characterized by their intangibility.

The challenge is served, any person or entity linked to the artistic, faces the difficult task of registering to preserve the immortality of the artistic event. These innovative and fleeting categories implicitly involve the participatory condition of the viewer, space as a continent and content of the work, time, extinction of materials, action, displacement, loss of the uniqueness of art, as well as its accelerated dematerialization Conditions and aspects that make art an "art-event", predisposed by the space-time condition to its expiration, modification or disappearance.

\section{Keywords}

Emerging art, dematerialization, documentation, mobile devices, fleeting art, preservation. 


\section{DIFICULTADES EN EL RESGISTRO Y TRANSMISION DE UN ARTE FUGAZ.}

\section{RESUMEN}

Desde la segunda mitad del siglo XX las intervenciones artísticas se independizan de los hartados y constantes componentes estéticos, miméticos y matéricos. La imposibilidad de custodiar la obra como objeto demanda nuevos mecanismos que registren un arte tan cambiante como caprichoso. Con los avances de la tecnología, la fotografía digital y las innovaciones acontecidas en el campo del arte, los artistas comenzarán a dejar constancia de sus intervenciones haciendo uso de cámaras fotográficas y pequeñas grabaciones para inmortalizar sus obras. Destinamos esta investigación a trabajar, a través de una representación de autores emergentes, las dificultades en el registro de obras artísticas caracterizadas por su intangibilidad.

El desafío está servido, cualquier persona o entidad vinculada a lo artístico se enfrenta a la difícil tarea de registrar para conservar la inmortalidad del acontecimiento artístico. Estas innovadoras y fugaces categorías llevan implícita la condición participativa del espectador, el espacio como continente y contenido de la obra, el tiempo, la extinción de los materiales, la acción, el desplazamiento, la pérdida de la unicidad del arte, así como su acelerada mortalidad. Condiciones y aspectos que hacen del arte un "arte-acontecimiento", predispuesto por la condición espaciotemporal a su caducidad, modificación o desaparición.

\section{Palabras Clave}

Arte emergente, desmaterialización, documentación, dispositivos móviles, arte fugaz, preservación. 


\section{INTRODUCCIÓN}

La incorporación y el uso de las primeras tecnologías finalizando el siglo XIX, fue claramente superado por lo que se aproximaba en el siglo XX. La presencia de cualquier dispositivo móvil con los que cohabitamos, ha supuesto una rebelión en todos los ámbitos de la sociedad y el arte no queda exento ante esta revolución, que avanza a un ritmo vertiginoso. La aparición y el desarrollo de herramientas tecnológicas han transformado el trabajo de los artistas, el mismo concepto del arte y sus campos de aplicación. El mundo ha cambiado, la forma de relacionarse con el arte se ha trasmutado de lo detenido a lo dinámico, de la pasividad a la actividad, de lo visual a lo multisensorial, de lo eterno a lo fugaz. Las tecnologías de la información y la comunicación están modificando profundamente nuestro mundo y la manera en la que nos relacionamos con el acontecimiento artístico. Las formas de hacer arte, sus lenguajes, el papel del artista, y la conservación de éste, parecen ser dependientes de lo tecnológico tanto para su creación, su recuperación o su difusión.

La relación del arte con las nuevas tecnologías y medios (video, realidad virtual, láser, digitalización, etc.), o con lo que Frank Popper llamó los medios de la era electrónica, ha derivado en múltiples prácticas que obligan a hablar de una nueva materialidad de la obra de arte, pero también de un nuevo tipo de relacionarse entre los artistas y científicos, y de un nuevo comportamiento del espectador ante el arte, un espectador que, en tanto que utilizador de un sistema inteligente, ya no se limita a intervenir, intelectual o comportamentalmente en la obra, sino que participa en ella. (Guasch, 2016, p.439)

Para una inmensa mayoría de nosotros, la Historia del Arte se basa en el conocimiento más o menos exhaustivo de un arte sustentado y representado por un objeto artístico. La producción artística se ha clasificado y acotado siguiendo las viejas categorías heredadas de las Bellas Artes. Ha sido siempre una constante imprescindible, la materialidad del arte y la autoría en manos de artistas dotados de un genio especial, haciendo de estas obras, objetos únicos e irrepetible, limitados a la contemplación visual y vetando la participación al resto de los sentidos del espectador.

¿Qué es el arte? ¡Vaya pregunta! El arte es la arquitectura, la escultura, la pintura, la música y la poesía en todas sus manifestaciones; tal es la respuesta que suele ofrecer el hombre corriente, el aficionado al arte incluso el artista mismo, suponiendo que el tema del que se habla está meridianamente claro y todo el mundo lo entiende de la misma manera. (Tolstoi, 2007, p.33)

Pero la Historia cambia y el arte que se genera a partir de la Segunda Guerra Mundial se transforma de manera radical. Hablamos actualmente de un arte señalado por la imperdurabilidad, por la forma en que los objetos se sitúan o posicionan y por la integración del espacio expositivo y el proceso como parte integrante de la propia obra. Un arte que se crea para un momento y para un espacio determinado, potenciando así producto artístico, tiempo y público. El arte queda influenciado y afectado en su representación por disciplinas como la danza, la música y el teatro. El espectador es invitado a sumergirse en las obras e interactuar con ellas en modo acción. En otras ocasiones el artista agrega, además de sus peculiares e inestables materiales, sensaciones térmicas, olorosas, sonoras o táctiles para definir y/o completar sus obras. Parece evidente entonces, que, si el arte contemporáneo es inconstante, versátil, fugaz, los mecanismos 
de registro deben cambiar a la vez. Nos planteamos en esta investigación cómo registrar el arte contemporáneo, un arte basado fundamentalmente en los procesos, conceptos e ideas, donde el objeto en sí, si es que lo hubiere, ya no es conservable pues puede, y tiende a su desaparición.

A partir de los años 60 del siglo XX, el contexto general en el que se situaban los artistas de la neo-vanguardia enfatiza el concepto y la experiencia por encima del objeto. Foster (2001) señala que: "Las obras huían del peso y de la presencia rotunda, y se reivindicaba la inmaterialidad como estrategia para evitar que las radicalidades de sus discursos se conviertan en un valor de cambio" (p.8).

Tras esta introducción, comunicamos el objetivo general que investigamos y que consistirá en considerar si la tecnología es apta, adecuada o capaz de registrar el arte contemporáneo. Para ello se ha seleccionado una muestra de artistas y sus trabajos, mostrando las nuevas e inconstantes condiciones del arte que emerge y forma parte de nuestra actualidad. Valoraremos tras esta muestra cómo el arte contemporáneo, para una futura transmisión, está unido al uso de dispositivos móviles con la finalidad de documentar el espacio artístico, el proceso, la experiencia y la acción como partes integrantes y condicionantes de la obra, aun siendo conscientes de que éstas, nacen ya con la particularidad de ser efímeras, caducas y perecederas.

Todo arte tiene una parte física, que ya no podemos considerar ni tratar como antaño, que ya no puede permanecer ajena al influjo del conocimiento y de las capacidades modernas. Desde hace unos veinte años, ni la materia, ni el espacio, ni el tiempo son ya lo que siempre habían sido. (Benjamin, 2017, p.7)

\section{EL ESPACIO Y EL TIEMPO EN EL REGISTRO DE LA OBRA DE BELÉN BLESA: SUB SPECIE AETERNITAIS}

No hay fronteras para el arte actual, surge en cualquier momento, en cualquier lugar, y esto es uno de los fenómenos más significativos del arte contemporáneo. Para soportar esta afirmación, se ha seleccionado la performance-instalación Sub specie aeternitatis realizada por la artista y docente Belén Blesa.

Se desarrolló el 11 de mayo de 2018 en el paraje natural de Las Flotas (Alhama de Murcia) con una duración limitada a unas pocas horas y destinada a un público caracterizado por la variedad y la heterogeneidad. Como elementos no invitados, destacaron el azar y la sorpresa que se convirtieron en los protagonistas más valorados de todo el evento.

El sitio físico escogido para la instalación, fue el patio de la casa de verano de la familia, con toda la carga emocional que suponía. El evento estuvo acompañado por la intervención de Juan Gallego Moya, tenor y docente en el área de expresión musical de la Universidad Católica de Murcia, que interpretó la pieza Mattinata de Leoncavallo de Ruggero Leoncavallo, envolviendo el acontecimiento artístico. Sonido, color, fragilidad, palabra, aroma, música, belleza, se articularon para crear un acontecimiento imprevisto, limitado en tiempo y forma. Sin grandes aspiraciones artísticas y carentes de tecnología de última generación, la libertad parece que fue el elemento perfecto y mejor aliado en su obra, componente con el que declaró sentirse bastante cómoda. Hemos seleccionado esta efímera exposición, precisamente por la temática de esta investigación, la difícil documentación del arte de nuestro tiempo. 
La obra nace de los momentos detenidos por Blesa convertidos en momentos de vida, una bicicleta, su "saber mirar" y un teléfono móvil, única herramienta invitadas a la construcción de su obra. Podría decirse que las imágenes entendidas como pequeñas verdades vitales, constituían una experiencia de percepción clara ${ }^{1}$, a modo en el que Maslow la concibe. En esta obra efímera, sitúa en el centro la experiencia de la eternidad, como acontecimiento vital², inspirándose para ello en el concepto de Spinoza. Contrasta de manera muy impactante la fragilidad de su obra fotográfica y los soportes en hierro oxidado, por los cambios climáticos que la contienen, formando una asociación perfecta entre continente y contenido; sin marcos, para que su obra se funda con la eternidad del material, convirtiéndose este en una prolongación del momento atrapado que soporta. Cada composición fotográfica se acomoda, a su vez, con un fragmento o aforismo que no habla de la foto, ni viceversa, sino que entre ellos se da una relación que abre otras posibilidades.

Con Sub specie aeternitatis no es que hayan cambiado muchas cosas, sino que ha cambiado la perspectiva de las cosas. Una instalación, la primera, trazada paso a paso durante unos tres años (...).En Sub specie aeternitatis experimenté la materialización de ideas con un lenguaje distinto al de las palabras.(...). El hierro fue el soporte de las fotografías que constituían pequeños bloques de eternidad en transición hacia distintas actividades de la vida cotidiana. El paso del tiempo como soporte de la eternidad. (Blesa, 2019, p.15)

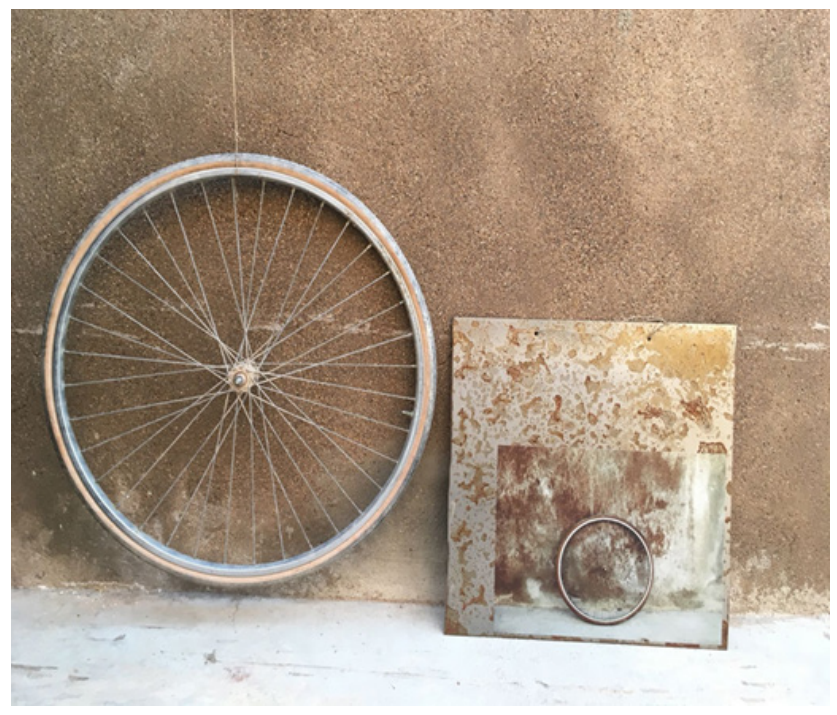

Figura 1. Belén Blesa, Sub specie aeternitatis, 2018.

\footnotetext{
1 Para Maslow, la percepción clara es una de las características de las personas autorrealizadas. Consiste en la capacidad para captar en algo o alguien, (una persona, un paisaje, una cosa) lo que es en sí mismo y no por la utilidad o agrado que te reporta, de manera desinteresada, sin hacerlo depender de la propia necesidad o proyección. Véase El hombre autorrealizado. Barcelona: Kairós, 1973. $2 \mathrm{El}$ concepto de Sub Specie Aeternitatis: la expresión fue acuñada por Spinoza en sus Principios Filosóficos, escritos en latín, Ethica more geometrico demostrata, Parte 5, Teorema 29. Traducida como desde el punto de vista de la eternidad.
} 


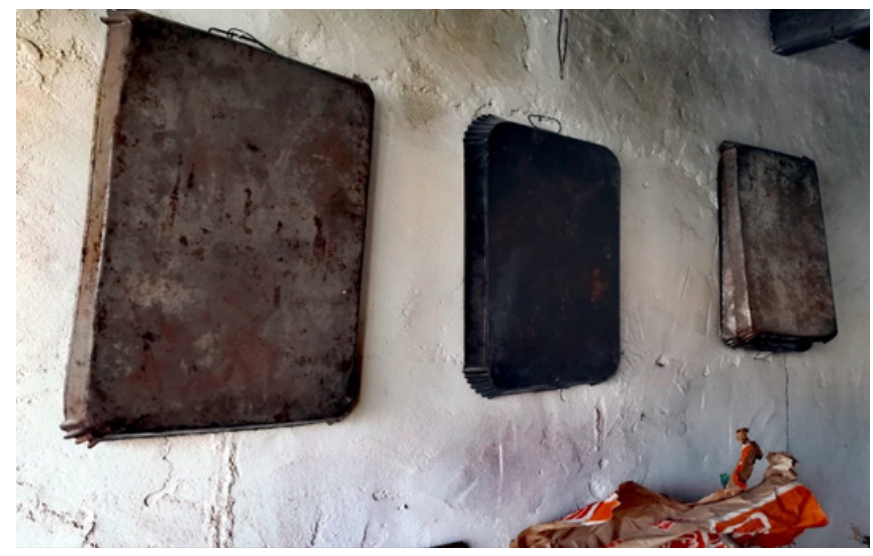

Figura 2. Belén Blesa, Sub specie aeternitatis, 2018.

Atendiendo a la conservación y futura transmisión de su obra, la artista declara en una entrevista concedida el 18 de mayo en la Universidad San Antonio de Murcia, ser consciente de que su obra ya está registrada por el público que asistió al evento. Añade que, para ella, el registro importante es el que se hace a nivel vital. Se trata de la experiencia singular que se genera entre el espectador y la obra. Nunca podremos acceder a ese tipo de registros porque se escapan, son emociones lo que suceden, lo que se construye y lo que lo sostiene, y eso es lo central, que se mueva algo en alguien. Apunta la autora que quiso hacer un experimento y dispuso un cuaderno para que los asistentes pudieran dejar escrita su experiencia de un acontecimiento que se construía a la vez que desvanecía. Afirma al finalizar su intervención que lo relatado fue muy emocionante. Para el registro y documentación la idea es un catálogo ${ }^{3}$, parece ser el sistema por el que se decanta Blesa que recoge fotos de la instalación y los textos que formaban parte de ella. Desea que este registro, como segunda obra, tenga lugar, pero para ella lo importante es la experiencia vivida y su huella en la memoria de muchas personas que estuvieron.

Ante una posible reexposición declara resultarle difícil, casi imposible pensar en la repetición porque fue muy consciente de presentar una obra efímera y eterna al mismo tiempo. De hecho, ese es el tema de la obra: la tensión entre el tiempo y la eternidad. No le produce ninguna nostalgia esa obra porque fue todo lo que pudo ser concentrada en ese momento. Con un poco de nostalgia relata que tuvo que aprender a soltarla, a no apegarse a lo que había sucedido. Su relación con la obra ha sido un trabajo personal. Ahora, en lo que piensa es en no repetir lo mismo en un futuro. Ahí hay una línea muy delgada entre, partir de la inspiración que le sigue produciendo Sub Specie Aeternitatis para crear algo diferente, o repetir la misma idea.

Declara que es consciente de lo difícil que es no repetirse. No quiere hacerlo. Sub specie aeternitatis, como obra, es irrepetible. Ante la cuestión de si el tiempo, la experiencia, el lugar, forman parte de su obra, Belén expone que tiempo, sin duda, como contenido y como elemento de la instalación Sub specie Aeternitatis hace referencia a pequeños bloques de eternidad experimentados en su vida cotidiana, en transición hacia algo. Es la experiencia del momento, presente, eterno, desencadenado al contacto con cualquier estímulo insignificante.

3 El catálogo de la instalación Sub specie aeternitatis, está actualmente en vías para su publicación, que recogerá algo de esa obra, pero no será ya la misma obra, ya no sabe si es un registro, cree que no. 
Como elemento de la instalación, el tiempo es evidente: vivir el momento presente, el carácter efímero, el para siempre de lo que sucedió.

Ante la cuestión planteada en referencia a la documentación de su obra y registro de toda su esencia Blesa declara ser consciente que en la actualidad no hay una documentación ni una publicación oficial exclusivamente destinada a esta exposición. Casi todas las personas que había en el evento hicieron capturas con su móvil: fotos y videos sobre todo. Si a eso se le llama documentación, la hubo. Lo que entiende que no ha habido ha sido una difusión de todo ese material en redes.

Se planteó la obra sin medios (tv, radio, tablet), quería que fuera una experiencia más íntima que social. Cree que las personas que estaban allí lo captaron, e intuye que guardaron el secreto. El arte tiene que ver con desvelar el secreto, pero el desvelamiento solo te hace consciente de que hay un secreto, legustaesa experiencia. Piensa que, aveces, la difusiónmal planteada, sobretodocuandose vuelve muyautorreferencial o con un deseo implacable de hacerse notar, machaca esa experiencia.

Cuando se le pregunta sobre los dispositivos móviles para la documentación, para transmitir la obra, declara que le parecen idóneos y al mismo tiempo, delicados. Idóneos porque pueden registrar saliendo de los formatos legitimados hasta ahora, delicado, porque en internet cualquier cosa se nos escapa.

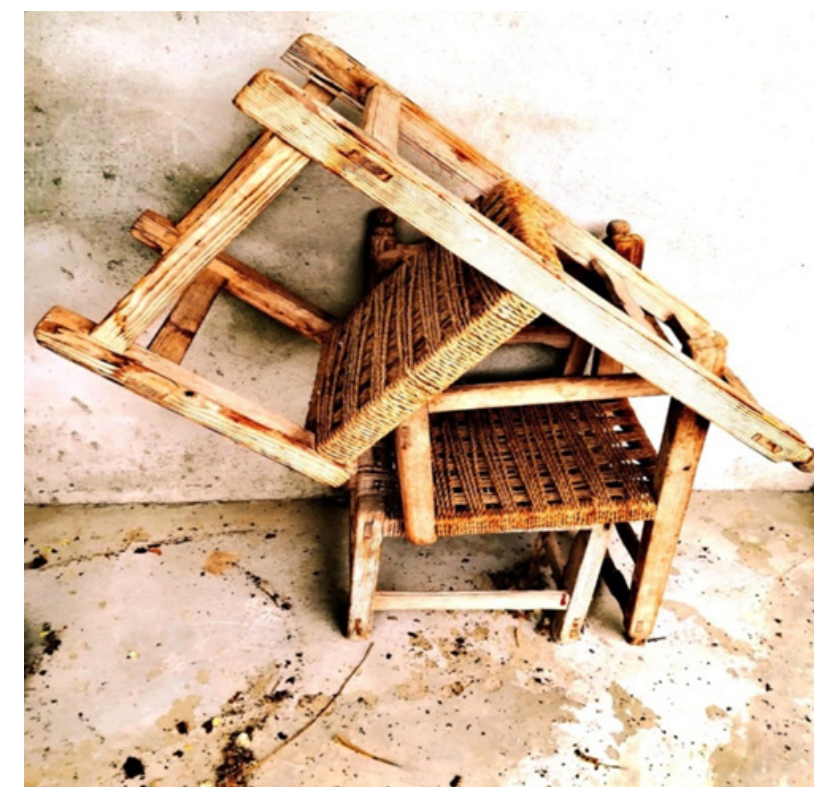

Figura 3. Belén Blesa, Sub specie aeternitatis, 2018. 


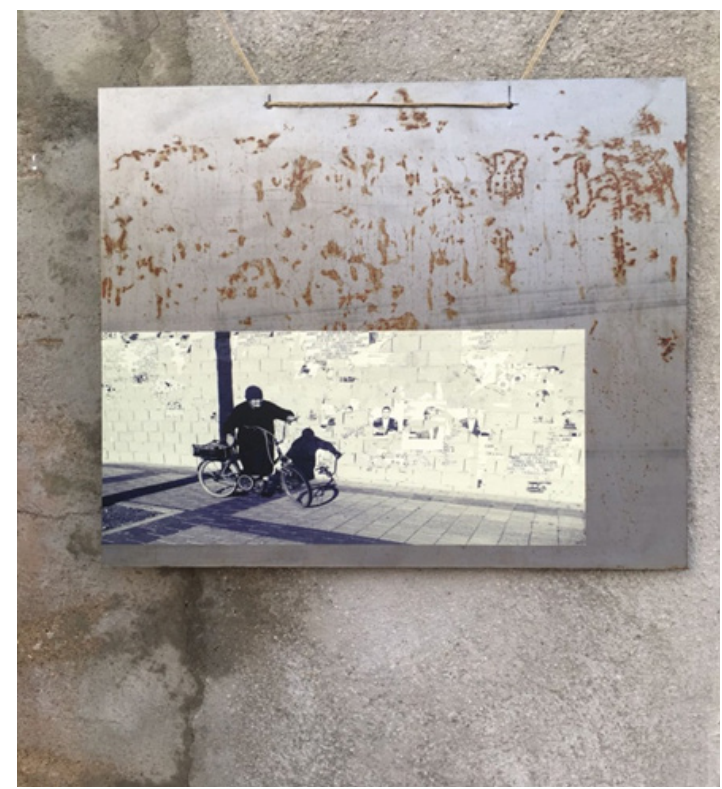

Figura 4. Belén Blesa, Sub specie aeternitatis, 2018.

\section{3}

Marc Augé, comenta que los recuerdos servirían de pantallas para las huellas, a veces aparentemente anodinas como un olor o un sabor, que son las que realmente disimulan y, al mismo tiempo, contienen el pasado. Sobre estas huellas puntualiza el antropólogo (1998) "están en cierto modo desconectadas de todo relato posible o creíble; se han desligado del recuerdo" (p.30).

Los artistas han trabajado y trabajan mayormente obras destinadas al sentido de la vista, siendo la contemplación visual la gran beneficiada. El oído, en lo que a piezas sonoras y musicales se refiere, también ha estado presente en disciplinas musicales y en relación con el arte. Kandinsky desarrolló con ejemplos gráficos la analogía que existía en sus obras entre la percepción musical y los colores que utilizaba en sus cuadros.

El estridente amarillo limón duele a la vista más que el tono alto de una trompeta al oído. (...) . Por ejemplo, el color rojo puede provocar una vibración anímica parecida a la de una llama. (...), podríamos explicar fácilmente por medio de la asociación los otros efectos físicos del color, es decir, los efectos no solo sobre el sentido de la vista sino también sobre los demás sentidos. (Kandinsky, 2017, pp. 52-53)

Emergen en la segunda mitad del siglo, obras destinadas a la participación del sentido del tacto, el olfato o el gusto. Para ejemplificar esta condición, nos referimos a Marina Abramovic (1975) en Lips of Thomas o Gina Pace (1972) en La Lait Chaud en donde se utilizan elementos como la leche, la miel o el hielo o el fuego. 
Nos detenemos en el caso de La Casa Encendida (Madrid) que acogió la exposición On \&On del 8 de noviembre de 2010 al 16 de enero de 2011 con la obra de Claire Morgan, entre otras. La instalación estaba realizada con fresas que colgaban del techo de la sala de exposiciones, amenazadas desde su origen por el propio proceso de descomposición. Una de las primeras exposiciones realizadas en España por artistas que trabajan con arte comestible con un alto componente oloroso y claramente caduco. El olor que desprendía la instalación de esta artista no es viable registrarlo, ni documentarlo, haciendo imposible, el registro total de la pieza. A esta condición hay que añadir que cada visitante contempló una versión distinta de la instalación, incluso si en el periodo que permaneció instalada se hubiese visitado la obra en varias ocasiones, la visión de esta obra no sería la misma. Obras tangibles sí, pero variables y acotadas en su existencia. Los primeros días de la exposición los espectadores percibieron un placentero olor a fruta fresca, conforme avanzaba el tiempo de exposición ese atractivo aroma se trasfiguró por su propio proceso de corrupción en un olor displacentero y desagradable. El interés de la obra radicaba precisamente en mostrar la importancia de componente olfativo y la fragilidad de estas instalaciones colgantes, que muestran los procesos naturales de descomposición de materiales efímeros y orgánicos.

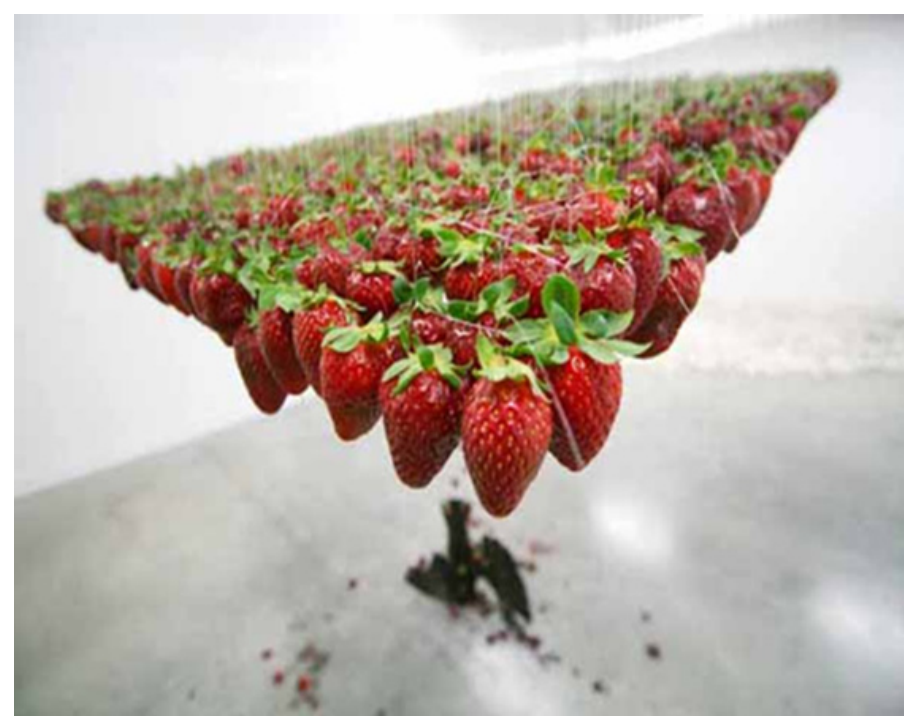

Figura 5. Claire Morgan. Fresas que van madurando, Poesía pendiente de un hilo, 2008. Fuente: https://www.afuegolento.com/articulo/onon-la-casa-encendida-madrid-exposicion-que-me-alegra-dia/386/ Fotografías de Kris Heath.

Mostramos otro ejemplo en la galería murciana Léucade que acogió de manera itinerante la obra del artista Alfredo Guillamón bajo la exposición titulada, Vértices: El arte del tacto. El atractivo de esta muestra, residía en interpretar la materialidad, composición y forma de las obras expuestas, mediante el sentido del tacto y el olfato, una propuesta divulgativa destinada a entender el arte a través de la sensorialidad. Para ello, el visitante tuvo que vendarse los ojos antes de acceder al espacio, poniéndose en el lugar de una persona con discapacidad visual. La galería tenía preparados unos antifaces, y unas cuerdas que hacían de guía durante todo el recorrido y que a la vez conectaba cada una de las piezas. Conforme avanzaba el espectador, en 
el punto marcado, podía pararse, coger la obra entre sus manos, olerla y activar el sentido del tacto junto a la imaginación que comenzaba su trabajo. Al final del recorrido. Guillamón invitaba a cada espectador a adquirir un trocito de hilo y a componer, como si de un artista se tratase, la obra central. Sofía Martínez, directora y propietaria ofrece una visión renovada del espacio expositivo dando cobertura a un público heterogéneo.

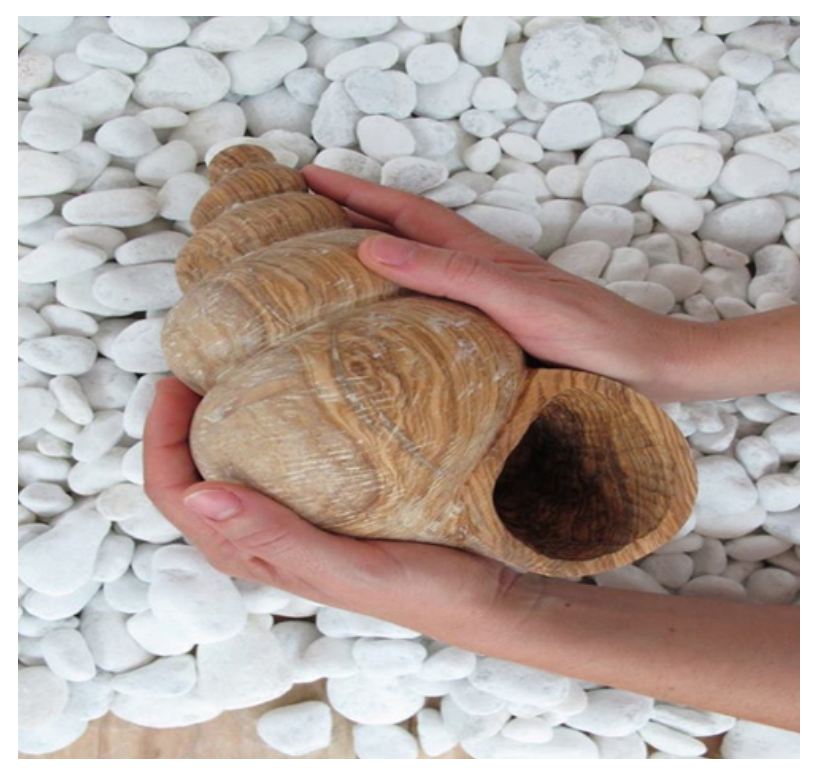

Figura 6. Alfredo Guillamón, El arte del tacto, 2014. Fuente:

http://cmonmurcia.com/111-hablamos-con-galeria-leucade-como-ver-una-exposicion- sin-verla/

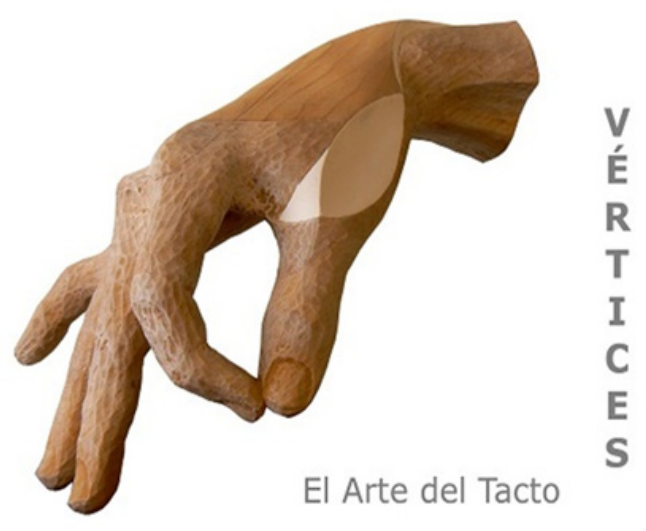

Figura 7. Alfredo Guillamón, El arte del tacto, 2014. Fuente:

http://cmonmurcia.com/111-hablamos-con-galeria-leucade-como-ver-una-exposicion- sin-verla/ 
Advierte que la idea de montar una exposición para personas con discapacidad visual fue el proceso para hacer esa idea realidad. Declara que tenía planeada una muestra individual con Alfredo Guillamón, y le propuso enfocarla para invidentes. Le entusiasmó que el artista aceptara. Apunta de él que es un gran artista y una gran persona, y le da mucha importancia a esa combinación, para la galerista es un todo. Además, fue la primera vez que se hizo una exposición destinada a este colectivo en una galería de arte de Murcia. Aclara que había un sistema para poder guiarte por la galería sin poder ver, y las cartelas estaban en braille atendiendo a las necesidades de este particular espectador. En esta misma línea, el artista Tarek Atoui $^{4}$ trabaja una colección de instrumentos bajo el título WITHIN que diseñó tras un largo proceso de aprendizaje con personas con discapacidad auditiva. Hasta el 12 de enero de 2020, se puede visitar su obra y la de otros artistas, el espacio CentroCentro, en el emblemático edificio del Palacio Cibeles. Esta exposición titulada Oído Infinito se realiza en colaboración con personas con discapacidad auditiva y está destinada a ser percibida por otros sentidos igualmente importantes para oír.

\section{LA OBRA DE IGNACIO LAMAS Y SU CONCEPCIÓN COMO UNA TOTALIDAD}

El artista Ignacio Llamas tuvo la amabilidad de recibirnos en noviembre de 2017 en Toledo, su ciudad natal y enseñarnos su obra, titulada Sangrar Luz. La exposición pluridisciplinar estaba compuesta por trabajos de obras volumétricas, fotografía e instalaciones.

Para la visita el artista, actuó primeramente dejando espacio y tiempo para que el espectador la disfrutase y la viviese, así lo entiende y así lo transmitió. Opina que se establecen dos tipos de relaciones en la obra: de manera secuencial, primeramente, el artista y la pieza y a continuación, la pieza y el espectador. En la web oficial del artista encontramos las siguientes declaraciones:

La principal función del arte es la comunicación de un contenido, es decir, aquello que de inmortal hay en el ser humano y que te permite establecer una relación con lo absoluto. Este contenido, mediante el cual se comunica algo del ser, atañe directamente al espíritu. Hacer que la obra de arte se convierta en un viaje interior, un viaje hacia el corazón de la humanidad. Viaje que lleva a cabo en primer lugar, el artista como creador y posteriormente lo realiza el espectador. (Llamas, 2017)

Su trabajo se basa en la contraposición de opuestos, blanco- negro, físico-espiritual, vacío-lleno, luces - sombras y en esta simbiosis de contrarios declara sobre la belleza que contiene también en sí la fealdad, se considera un transmisor de la obra. La obra es atemporal y universal. El artista concibe su obra como una instalación, controlando todos los elementos que intervienen en el montaje y el proceso expositivo al igual que el comisario. Una idea especialmente interesante para nosotros es la que el artista declara en una entrevista para el programa "Otras miradas"5 de la TV Diocesana en octubre de 2017. Expresa que concibe la exposición como una obra efímera.

\footnotetext{
$4 \mathrm{El}$ uso que hace del sonido desafía y expande nuestras maneras habituales de entender y experimentar este medio. Su proyecto WITHIN, por ejemplo, parte de la Cultura Sorda para encontrar nuevas formas de construir instrumentos, así como de componer y de ejecutarlos. El diseño de los instrumentos y su capacidad para tocarlos son el resultado de talleres y estancias en las que Atoui ha trabajado con personas sordas y con hipoacusia, fabricantes de instrumentos acústicos, diseñadores de altavoces, ingenieros de software y compositores. Información disponible en: https://www.centrocentro.org/exposicion/oido-infinito. 5 Puede consultarse la entrevista completa en https://www.youtube.com/watch?v=s8gx9sHgN_E
} 


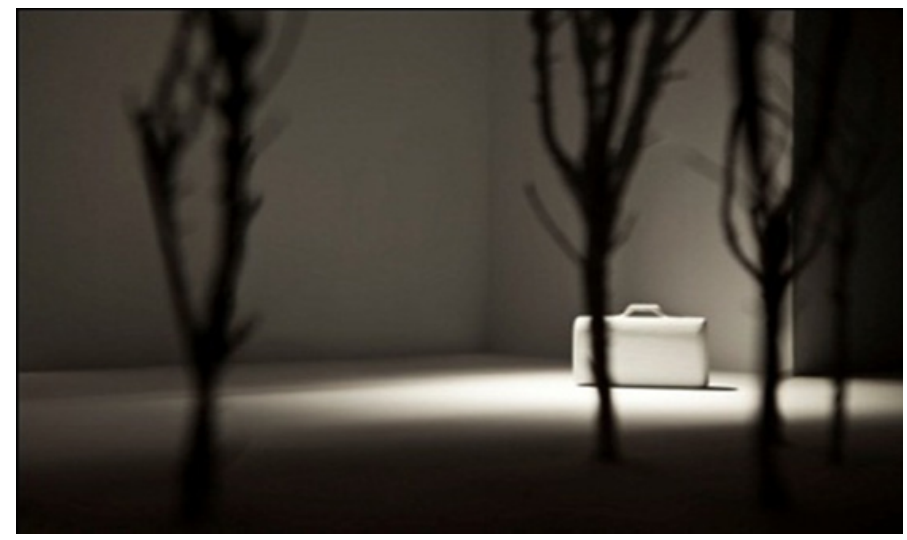

Figura 8. Ignacio Llamas, Sangrar luz, 2017. Toledo. Fuente: http://www.ignaciollamas.es/Espanol/intro-espanol.html

Ante la necesidad de contar con un testimonio actual, nos planteamos escribir al artista y nos concedió una entrevista telefónica el 17 de abril de 2018 a las 10:00 h desde el estudio donde se encontraba trabajando. Llamas se presta a contestarnos a las preguntas planteadas con respecto a la conservación y transmisión de su obra.

Comenzamos la charla anunciando que, ante este tipo de instalaciones que el artista quiere conservar, y por las nuevas condiciones en las que se trabaja, es muy difícil el registro en toda su integridad. Mostramos en este momento cómo algunos artistas declaran que lo que se conserva, se guarda o se adquiere es el concepto de la obra, como es el caso de Olafur Eliasson ${ }^{6}$; otros se niegan rotundamente como declara Gilman (2015) sobre Zoe Leonard7 que se niega a someter la pieza a procesos artificiales de conservación. El espacio y el tiempo son condicionantes en ocasiones y parte fundamental para el sentir de la obra, aspecto sujeto a cada espectador e incapaz de ser registrado. Atendiendo a la materialidad de la pieza, ¿̇el registro de esa obra, mediante dispositivos móviles, sería una posible opción?, Gilman (2011) afirma que cuándo un museo, galería o fundación obtienen la obra como es el caso del Museo Municipal de Arte Contemporáneo de Gante con la obra de Artur Barrio, automáticamente el conservador comienza el proceso de registro mediante fotos, videos al pasar a ser propiedad de la institución que las obtiene.

A este tipo de cuestiones, el artista declara que, centrándonos en la obra, para él es muy importante la materialización. También es igual de primordial la exhibición de la obra, puesto que su trabajo es bastante instalativo, por las condiciones de la luz; por el acceso a la obra; el recorrido previo; las condiciones de sonido. Todo es fundamental y para Ignacio construye la materialidad del arte. Llamas piensa que en obras como la suya, tratar de preservar solamente el objeto, es perder gran parte de ella.

6 Las declaraciones de Olafur Eliasson sobre la adquisición del concepto de la obra, pueden consultarse en el documental Installation Art: Who Cares? .Disponible en: https://www.youtube.com/watch?v=viwshM95Kaw 7 En el caso de Zoe Leonard, Gilman (2015) relata cómo Ch. Sheidemann dedicado a la conservación, planteó "una posible solución a sus piezas de fruta, que consistía en un sistema de enfriado rápido y posteriormente remojarlas al vacío en un aglutinante Paraloid B72. Zoe se negó por considerar que la degradación de las piezas formaba parte de la obra. 
En su caso, hay piezas en las que no sería posible un cambio o sustitución en la materialización, porque son obras únicas y exclusivas y la mano del artista tiene bastante protagonismo y luego, hay otro tipo de obras como la fotografía, que lleva consigo un proceso industrial en el que el artista también tiene mucho que decir. Pero aun así, cada vez que tiene que hacer una foto, no llama al laboratorio, sino que se desplaza a la obra buscando el punto de luz necesario porque aunque te aseguran es siempre la misma, no es verdad. Para el toledano la magia está en ese pequeño detalle del tratamiento del color, de la intensidad de la luz, y resulta fundamental cuidar esos detalles porque son elementos importantes y parte de la materialización. Con respecto a las exposiciones, su obra, no es efímera en general o una parte de su obra, que sería la parte más escultórica, fotográfica, pero hay otra parte de instalaciones que sí son efímeras, ya que la exposición para él va siempre unida al propio espacio. En cuanto cambia el lugar, el concepto se mantiene, pero la materialización de la obra es totalmente distinta. Para este artista, las exposiciones tienen un signo de obra, por el carácter instalativo, hay una parte efímera que es difícil recuperar porque por mucho que se hagan planos, se estudie la luz, las mismas condiciones no se pueden reproducir ya que el espacio es diferente, la forma de acceder es diferente. Le preguntamos a Ignacio si le parecería más adecuado para cierto tipo de intervenciones hablar de documentación incompleta en lugar de documentación total mediante tecnología móvil. Le parece adecuado, así como el uso de cualquier dispositivo, siempre cuanto más profesional, mejor. Ignacio piensa que, tal y como se presenta el arte contemporáneo, haría falta una figura fundamental que sería la del intérprete, que estudiase la obra y fuera fiel a lo que el artista quiere contar, ya que la obra deja de ser objeto y se convierte en instalación tal y como se presenta el arte contemporáneo. Sobre todo, con el tema de la instalación, la importancia que tiene el propio espacio. El público cada vez es más consciente de las condiciones de la obra hasta ahora en manos de técnicos que van con patrones establecidos y que no diferencian el montaje de un artista u otro.

Ignacio nos cuenta cómo la instalación del grupo escultórico de los Chinos Thirteen Laughing at each other (2001) de Juan Muñoz, vista en Madrid y en Bilbao, era totalmente desemejante, contando el mismo concepto de una forma diferente. En una de las exposiciones, los chinos están aislados, y en otra, se relacionan entre sí. Lo que le lleva a pensar que la figura del intérprete puede ser interesante. Llegamos a la conclusión de la necesidad de vinculación que debería existir entre un artista y el intérprete, de esa manera las obras serían iguales en cualquier sitio donde se mostrasen. Desde luego, cuanta más documentación exista de cómo se instalan las obras, de lo que piensa el artista cuando monta una determinada obra, más posibilidades hay de ser fiel a esa idea. Cualquier dispositivo es válido. El montaje de la exposición influye de manera rotunda en la manera de ver las obras. Ignacio hace referencia a una pieza de Iturralde que no necesita ser explicada ya que la propia atmósfera de la exposición la explica: el círculo como movimiento constante, con referencias conceptuales que genera la propia exposición, todo influye y es importante en la percepción de una obra. Cuanto más propensa sea la atmósfera de la obra, más propenso está el espectador para llegar a ella. Le comentamos al artista que vamos a reproducir con su permiso estas ideas, a lo que muestra su total y rotundo consentimiento. 


\section{LA DESAPARICIÓN DEL OBJETO COMO PARTE ESENCIAL DE LA OBRA: NELÉ AZEVEDO Y SU MONUMENTO MÍNIMO}

Un ejemplo de esta condición del arte contemporáneo lo encontramos en las intervenciones de Nelé Azevedo, concretamente en su Monumento mínimo. Artista urbana de origen brasileño que se caracteriza por el uso del hielo en espacios urbanos, mostrando por medio de éste la fragilidad del ser humano, que, ante el paso del tiempo, independientemente de la posición social, (reflejada en la colocación de los hombrecitos en las escaleras), de la edad, sexo, somos iguales, ¿ante la muerte?, quizá.

Otro posible discurso conceptual ha sido que su obra sirve para levantar la voz y concienciar sobre el cambio climático y el deshielo de los glaciales. A través de sus frágiles piezas, Acevedo pretende mentalizar al igual que los artistas que trabajan vinculadas al Land Art de los daños que el hombre causa al planeta. Estas intervenciones espaciales se ejecutan en un espacio específico y para un tiempo determinado; la desaparición de la obra es total y parte fundamental de su significado. Sin su destrucción, no tendría sentido, es más, llegaría a trasmitir una idea o un mensaje totalmente contrario al que la artista pretende comunicar y para lo que ha sido diseñada y creada la instalación.

Azevedo sienta cientos de hombrecitos de hielo en plazas y espacios públicos muy transitados, mostrando cómo las piezas se derriten por las condiciones climáticas. Su trabajo hace un llamamiento de urgencia al ser humano y sus actuaciones que están generando un excesivo calentamiento global. Azevedo no ha podido elegir mejor material para su instalación. Cualquier caminante que transite por la zona observará cómo los hombrecitos van desapareciendo, al igual que lo hará el planeta si no se preserva, es una responsabilidad de todos. Es por esto por lo que se coloca una gran cantidad de esculturas, invocando no solo a políticos y agentes medioambientales, sino a todos y cada uno de nosotros. En otras ocasiones usa estas frágiles esculturas para recordar y conmemorar a víctimas de conflictos bélicos que no son recordadas. En estas instalaciones los hombrecitos que se derriten han viajado por todo el mundo, se han mostrado en La Habana, Berlín, Florencia, París, Tokio, Singapur y la Ciudad de México, por mencionar algunas.

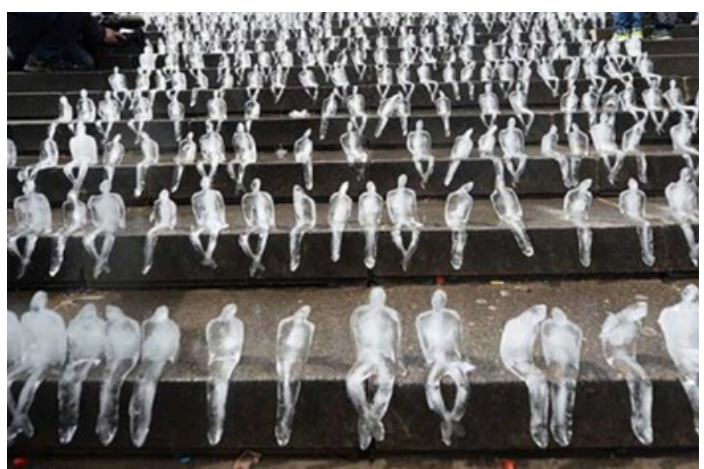

Figura 8. Nelé Azevedo, Monumento mínimo, 2008. Escaleras de Chamberlain Square, en Birmingham, Reino Unido. Fuente: http://www.accionpreferente.com/mundo/5-mil-esculturas-de-hielo-recordaron-a-las-victimas-de-la-igm/ 


\section{Conclusiones}

Cuando pensamos en la conservación del arte, de manera casi automática, nuestra mente nos reseña a los procesos que, casi visualizamos protagonizados por grandes profesionales dedicados a la gestión, cuidado y restauración de monumentos y piezas artísticas, tangibles al tacto. El arte queda entonces bajo amparo de mecanismos y espacios que albergan condiciones óptimas para su mantenimiento y protección. Esta habitabilidad en circuitos culturales permite resguardar las obras, preservarlas y asegurar así su inmortalidad frente al amenazante transcurrir del tiempo. Vuk Cosic, en la entrevista con Cilleruelo y Crego en (2002) así lo expone:

El potencial de la tecnología más actual no está cambiando solo el proceso creativo, sino incluso la misma naturaleza de los papeles de creador y espectador. La difusión de la obra artística, por ejemplo, es uno de los aspectos que se está viendo más transformado. En gran medida muchas de las nuevas formas de arte se basan en las características de acceso individual y a distancia que la tecnología actual permite, generando así frecuentemente un abanico de diferentes y singulares propuestas artísticas, para las que se necesita una sensibilización nueva.

Partimos de una premisa básica, sea como fuere, el arte contemporáneo, de una manera u otra llega al espectador de una forma parcial, fragmentada o en su totalidad y ha llegado a nuestro siglo de muy diversas maneras. Añadimos que todo artista desea que su obra se conserve. Pongamos por ejemplo las declaraciones de Richard Long en una entrevista con Castro Jorquera publicada en Artishock, revista de arte contemporáneo el 20 de octubre de 2014; declara esta vez en relación a su obra y la caducidad de ésta, que depende de la cámara fotográfica: "si yo no tuviese una cámara no podría mostrarle a nadie lo que había hecho. Por lo tanto, tomar una fotografía es una de las maneras como puedo compartir mi experiencia".

Si no pudiese compartir mi experiencia, no tendría sentido ser un artista. Tengo diferentes maneras de compartir mi experiencia. La fotografía es una de ellas, trabajar con texto es otra, hacer una escultura en una galería es otra, hacer un gran trabajo con barro con mis manos es otra... así que tengo muchas maneras diferentes de presentar mi trabajo al mundo, y eso me interesa. (Long, 2014)

El problema de la restauración, conservación del arte para disfrute de las futuras generaciones o para su registro por ser una parte material de nuestro patrimonio, ha sido una firme preocupación a lo largo de la historia.

La perdurabilidad de la obra de arte parece estar ligada a la eternidad y ha estado en mente de conservadores, restauradores, curadores, comisarios y en los propios artistas desde los comienzos. Todos o casi todos han sido conscientes de su preservación mediante el uso de técnicas y materiales adecuados. Ahora bien, la diversidad de formatos y nuevas vías artísticas que surgen en el arte contemporáneo obligan a crear nuevos sistemas de documentación, catalogación, estudio e investigación.

Michèle Laird en un artículo de (2012) titulado Para salvar el arte contemporáneo de la autodestrucción nos explica cómo los restauradores, desde los años 70, trabajan en la investigación de nuevos métodos para la conservación de la obra contemporánea sujeta a unas condiciones sin precedentes. 
Presentamos la imposibilidad de documentar de manera total la obra, convencidos que el arte contemporáneo, por sus particularidades, no puede ser registrado en su integridad ni en toda su realidad. Entran en juego experiencias multisensoriales, las experiencias del espectador participante y los lugares junto al tiempo como componentes esenciales en las obras y los procesos artísticos. El arte contemporáneo, con el uso de nuevos materiales y el avance de las tecnologías, que en breves periodos de tiempo se quedan obsoletas, hacen que sea muy compleja la labor de conservar las obras para su posterior difusión, estudio o investigación ya que, de manera rápida, se autodestruyen y desaparecen.

Se ha generado el debate de si las obras de arte contemporáneas deben ser conservadas o no, cuestión todavía presente en nuestros días, parece que los dispositivos móviles tienen un gran reto por delante. En estas avanzadas tecnologías está recayendo la enorme responsabilidad de conservar, recuperar y documentar tanto el pasado, como la más inmediata actualidad artística o convertir su producto en obra matérica inmortal. 


\section{Bibliografía}

Alcolea, M. (2014, 19 de noviembre). C'Mon Murcia. Recuperado de C'Mon Murcia.com: https://cmonmurcia.com/111-hablamoscon-galeria-leucade-como-ver-una-exposicion-sin-verla/

Augé, M. (1998). Las formas del olvido. Barcelona: Gedisa.

Benjamin, W. (2017). La obra de arte en la época de la reproductividad mecánica. Madrid: Casimiro.

Blesa, A. B. (2019). Bestiarorum Curriculum. Meditaciones acerca del acontecimiento (en la academia). Salamanca: Amarante.

Gilman, J. (2011). La toma de decisiones en la conservación en obras de arte efímeras con alimentos. En A. Castilla, Arte contemporáneo en sala de guardia. Madrid: Teseo.

Kandinsky, V. (2017). De lo espiritual en el arte. Barcelona: Paidós Estética.

Cilleruelo, L. y Crego, J. (2002) Algunas cuestiones sobre arte y tecnología. Catálogo del festival música Ex Machina, MEM Codex. disponible en: http://www.pent.org.ar/debates/especial/arte.pdf

Foster, H. (2001). El retorno de lo real: La vanguardia a finales de siglo. Madrid: Akal.

Guasch, A. M. (2016). El arte último del siglo xx. Del posminimalismo a lo multicultural. Madrid: Alianza Forma.

Castro Jorquera, C. (2014). Richard Long: Mi trabajo es sobre las ideas de libertad. Hago arte casi de la nada. Artishock. Recuperado de http://artishockrevista.com/2014/08/18/richard-long-trabajolas-ideas-libertad-hago-arte-casi-la-nada/

Laird, M. (2012). En busca de la eternidad. Para salvar el arte contemporáneo de la autodestrucción. Swissinfo. Recuperado de https://www.swissinfo.ch/spa/cultura/en-busca-deeternidad_para-salvar-el-arte-contempor\%C3\%A1neo-de-laautodestrucci\%C3\%B3n/34574360

Llamas, I. (s.f.). Ignacio Llamas. Recuperado de www.ignaciollamas.es: http://www.ignaciollamas.es/Espanol/intro-espanol.html

Maslow, A. (1973). El hombre autorrealizado:hacia una psicologia del ser. Barcelona: Kairós. 
Spinoza, B. (2018). Ética: demostrada según orden geómetrico. Madrid: Alianza Editorial.

Tostói, L. N. (2007). ¿Qué es el arte? Navarra: Eunsa. 